\title{
How Digital Platforms Can Trigger Cultural Value Co-Creation?-A Proposed Model
}

\author{
Maria Vincenza Ciasullo, Orlando Troisi, Silvia Cosimato \\ Department of Business Sciences, Management \& Innovation Systems/DISA-MIS, University of Salerno, Fisciano, Italy \\ Email:mciasullo@unisa.it, otroisi@unisa.it,scosimato@unisa.it
}

How to cite this paper: Ciasullo, M.V., Troisi, O. and Cosimato, S. (2018) How Digital Platforms Can Trigger Cultural Value Co-Creation?-A Proposed Model. Journal of Service Science and Management, 11, 161-181.

https://doi.org/10.4236/jssm.2018.112013

Received: December 18, 2017

Accepted: March 10, 2018

Published: March 13, 2018

Copyright () 2018 by authors and Scientific Research Publishing Inc. This work is licensed under the Creative Commons Attribution International License (CC BY 4.0).

http://creativecommons.org/licenses/by/4.0/

\begin{abstract}
Starting from an overview of the current trends in ICTs and adopting a SD Logic perspective, the paper is aimed both at analyzing users' engagement in the e-cultural value co-creation process and at proposing a theoretical model conceptualized to shed lights on the interactions occurring between users and culture organizations that led to the (co)creation of value-in-context. The paper starts with a theoretical-conceptual analysis about the digitalization process and focuses on the impact that this process has had on culture heritage domain. The proposed theoretical model specifies which mechanisms the digital capabilities enable for co-creating e-cultural value. Even though the paper lacks an empirical validation, it offers a concrete exemplification of the proposed model. Thus the paper conceptualizes a theoretical model which provides interesting suggestions that help heritage managers in adopting strategies able to shape a cultural service ecosystem. The originality of this conceptual research lies upon its contribution in deepening the understanding about e-cultural value co-creation process and in conceptualizing a model based on the concept of value in context.
\end{abstract}

\section{Keywords}

E-Cultural Value Co-Creation, Value in Use, Value in Context, Engagement Platform, Theoretical Model

\section{Introduction}

The pervasive and worldwide information disclosure enabled by technologies and digitalization and the rise of the cultural tourism has contributed to change not only the current notion of cultural heritage, but also the related managerial practices. This has led scholars to address much of their research efforts on the topic [1] [2] [3], mainly focusing on the service and experiential dimension of 
cultural heritage, understood as strategically superior as its mere exhibition dimension [4] [5]. In this scenario, cultural organizations (e.g. museums, art galleries, libraries, archaeological sites, etc.) need to embrace a brand new role; they are no more intended as passive education channels, but as real experience providers [6] [7] [8]. Several are the research domains that have adopted this perspective; thus, the most representative of them are service marketing and management and consumer behavior [9] [10] [11] [12] [13]. The most of literature agrees that cultural value creation calls for more and more driven involvement of the users/beneficiaries in the value creation process [1] [14] [15] [16]. In this vein, cultural value does not merely arise from additional services intended to make experience as enjoyable as possible, but from an active process of enhancement based on the user's perspective and pointing to boosts his/her participation to value creation process. It becomes evident that cultural value is not pre-defined with the offering, but it is co-created or emerging from the interaction with the user. In light of this considerations, SD Logic [17] [18] framework offers a holistic understanding of how, in the complex context of cultural heritage, value is co-created through users' involvement and their ongoing experience exchange. This implies a rethinking of the inner meaning of cultural product which has shifted not only from its intrinsic value towards value-in-use, but has also done a further step forward to value-in-context, phenomenological created and shaped by a peculiar context. More in details, the co-creation of value-in-context is strictly dependent not only on actors' disposition in sharing and integrating their resources, but also on the inner characteristics of the context in which they interact [19]. Technological platforms designed and developed through digital technologies-boosting the connection and the interactions among a growing number of users other than the provider-customer dyad-have contributed to deeply change the processes of cultural value creation [20]. In fact, they can shape that immersive, interactive and virtual context in which culture can be experienced and e-cultural value can be co-created.

It has to be noted that even if some recent contributions [21] [22] [23] delve on the effect that digitalization has had on value creation process, literature is still calling for further research aimed at investigating how digital artefacts can support the co-creation of cultural value. Further investigation is also needed to shape a theoretical model able to offer a better understanding of how e-cultural value is co-created.

The study aims to contribute to bridge this gap shedding lights on both the importance of digital lever and the need for a managers' effort in capitalizing its potential, turning it into a real and no longer potential benefit.

The remainder of the paper is organized as follows: The next section describes the research aims and the inquiry questions, while the third section discusses the theoretical background at the roots of the proposed conceptualization of e-culture. The fourth section delves on the presentation of the proposed model, while the fifth section offers an exemplification of the above-mentioned model. 
Follows are the last two sections which discuss the theoretical and managerial implications, paving the way for further research.

\section{Research Aims and Inquiry Questions}

Drawing on the review of the scientific literature focused on the process of digitalization that has interested the cultural context and according to the recent advancement of value co-creation according to the SD Logic framework [17] [24] [25] [26] the purpose of this study is twofold. On the one hand, it aims to pointing out the role that digital technologies play in boosting actors' involvement in value creation process; on the other hand, this has led to overcome the traditional meaning of cultural product, going beyond a Good Dominant perspective of culture and, in so doing, prosing a theoretical model, defined e-cultural co-creation. Therefore, study points to respond to the following research questions:

$R Q 1$ : How the digital lever changes the interactions between users and cultural organizations?

$R Q 2$ : Does it exist a possible managerial model able to explain the value co-creation dynamics among and between users and cultural organization?

To address the first question, the specific socio-cultural scenario is investigated, mainly focusing on the way the most recent digital technologies lead to re-interpret culture according to a service logic. The second research question is addressed proposing the concept of e-cultural value co-creation and marking the difference between value-in-use and value-in-context [24]. Then, the conceptualization of value-in-context in the cultural domain, enabled by digital platforms, boost the implementation of the managerial model.

\section{Theoretical Background}

\subsection{The Exploitation of Digital Era}

The overwhelming impact of ICTs and of the related process of digitalization on every side of human though and activity is currently considered as both a driver of development and an indicator to assess the cultural capital of individuals, organizations as well as countries. Thus, it can be assumed that digitalization is one of the most pervasive transformation that has affected the contemporary society, involving both business activities and all the aspects of individuals' everyday life. In fact, the digitalization is more than the mere technical process of coding analogic information into a digital format (digitization), marking new socio-technical structures through digital artefacts and changing the artefacts themselves. It follows that these technologies are more than a set of hardware and software components, representing instead an innovative way of thinking that drive the way individuals approach the world [27].

The modern society is standing not only to a simple change in communication style, but it is witnessing to a real revolution that has led the informative architecture to achieve a new centricity in society as well as in the rethinking of both 
individual and systemic interactions. In fact, the turn of the millennium represented a cornerstone for the development of digital technologies such as the pervasive computing, the Web 2.0, the service-oriented architectures, the cloud computing and the open source software. The massive amount of new digital technologies is still changing not only the daily life of human beings, but also markets and organizations' configuration, creating a technological discontinuity that paves the way for overcoming the industry boundaries as well as the emergence of new business models [28].

To better understand the disruptive nature of the above-mentioned revolution it worth to divide it into different and subsequent macro-phases:

1) During the first era of digitalization the Internet or what we now call the Web 1.0 or "read-only-web" [29] acted as passive, static and unidirectional user-oriented mediator; in other words, as push-mediator [30] characterized by a strong separation between information providers and users, just considered as passive information receivers. More in detail, during this stage there was no active communication or information flow from users to provider and users' interactions or their content contribution were very little; thus, a huge amount of static websites populated the Internet.

2) The era of the so-called Web 2.0, a term used for the first time in 2004 by Dale Dougherty the vice-president of O'Reilly, was characterized by a shared wisdom, people-centric, participative and "read-write" web [31]. These characteristics opened up to users' contribution in content generation and to their interaction with others [29]. This led to the spreading of the so-called User Generated Contents (UGCs), which added to the renewed informative potential and to faster information flows made the Internet a really participative arena, populated by a plethora of social platforms (e.g. Facebook, Twitter, YouTube, Instagram, etc.) which empowered the common users making them capable at creating, uploading or reviewing web contents [32]. Due to the above-mentioned changes, also the informative and the cognitive system radically changed, shifting from a top-down informative architecture, characterized by one-to-one/one-to-many information flows, towards an open architecture in which information flows with not constrains according to a many-to-many orientation [33].

3) The next step forward led to the rising of what John Markoff, a journalist at the New York Times, defined in the 2006 as the Web 3.0 or "read-write-execute" web [31]. The Web 3.0 is also known as semantic web, characterized by the exploitation of semantic mark-up, semantic search and web services, which point to make the web readable not only by humans, but also by machines. In particular, the semantic mark-up is related to the communication gap between human web users and computerized applications. The semantic search is based on a system of tagging and meta-tagging that boosted the informative potential of the Internet as an open arena for the interactive communication, learning and content sharing [34] in which the user play an active and central role [35] [36]. Finally, web services are software systems designed to boost online com- 
puter-to-computer interactions.

4) The advent of the Web 4.0 or "mobile web" has not completely changed the Internet and its potential, but it has offered some sort of alternative version of the current Internet. Thus, adapting the web to the mobile surrounding, the Web 4.0 is able to connect in real-time all the available devices in both the real and virtual world [37].

5) The last step forward is represented by the Web 5.0, which is still and underground idea, lacking of punctual definition. However, it is currently represented as a "symbiotic web" rooted on the interaction between humans and machines made possible through mind-controlled interfaces. More in details, the idea at the core of the Web 5.0 is that machines would be able to read web contents and react to them, autonomously deciding the action to execute [38]. Consequently, it sounds like parallel to the human brain, offering a massive amount of online smart interactions. For this reason, the Web 5.0 has been also defined "emotional" web [39], paving the way for further developments and applications of neuro-technologies.

Drawing on the previous evolutionary steps, it worth noting how pervasive the digitalization represents the plethora of digital tools and artefacts which currently populate the Internet and which are under an on-going evolution [40]. The most popular of them are the multimedia applications, the socio-participative communication of social media and social networks, the content sharing platforms (e.g. Blogs, Wikis, RSS feed, etc.) as well as the ubiquitous connection that the current mobile applications offer. From the software engineering supply side, flexible and adapting projects and integrated development systems have been gradually implemented, shaping a fluid, dynamic and participative approach that follows a user-oriented logic, more than a customer-oriented logic [41].

More in details, a radical change in consumption habits has been due to digital users more demanding for the "consumption" of online information [42] and also for freely interact and joint together through online platforms. The escalation of online practices has contributed to change consumption behaviours [16]; thus, customers can now explore and recombine information in order to live new and rich experiences, thanks to the "datatification" of their daily activities which also led to fade away or, sometimes, completely break down the boundaries between real and virtual life in a blended world, in which physical experiences are intertwined with digital ones. This new behavioural trend is irrupting in several domains (e.g. transportation, baking, retail, tourism, culture, etc.), leading companies to rethink their strategies as well as the processes through which they interact not only with customers, but also with users in order to be complying with their changing habits and expectations.

\subsection{ICTs and Digital Technologies for the Enhancement of Cultural Heritage}

In this scenario, digital technologies represent a real and effective source of in- 
novation [20], because they have deeply influenced the way heritage artefacts are managed and made visible or accessible to the public [43]. Thus, multimedia information systems, rooted on the Internet and social media, can implement immersive technologies such as virtual environment and augmented reality to support and enhance cultural experiences. This new digital scenario, representing a real source of innovation for cultural institutions and organizations [44] [45] [46], calls for a rethinking of cultural value propositions.

Cultural organizations can use ICTs and specific digital tools following their mission statements: 1) the preservation and care of monuments, natural spaces, collections, documents or any other heritage artefact; 2) the welcoming and the educating of audiences to interact the artefacts; and 3) communicating with the surrounding environment in which public institutions, local authorities and people usually act. In this way, cultural organizations can improve their ability in storing and preserving a massive quantity of heritage artefacts in a faster, reliable, accessible and profitable way [47]. However, a more proactive managerial approach boosted by strategies can led cultural organizations to digitalize the overall servicescape [48] and consequently to the rising of the so-called interactive museums, virtual archives and digital libraries [49].

Digital libraries (e.g. Library Thing and The Open Library) often use collaborative indexing system based on the tag clouds, which record the books through users' keywords with the aim of enhancing the quality and the effectiveness of them researches. Sticking on museums (e.g. National Museum of Scotland and the London Grant Museum of Zoology), they even more frequently use the QR codes in order to make visitors with mobile devices capable at quickly finding out information about a specific heritage artefact. They have also promoted the implantation of geo-localization systems that make visitors always in touch with what happens near them or, in other words, with the so-called Points of Interest (POI) [50]. Focusing the attention on museums, [51] conceptualized and defined what a Participatory Museum is, a museum which artefacts can be observed through an open-access platform that make users able to freely consult, discuss and debate about the visualized artefacts. More in details, a participatory museum mainly aims at encouraging visitors educational and leisure participation through a highly personalized cultural offering able to enhance new interactive and comparative exchanges.

In sum, digital technologies can offer a more immersive fruition of the wide cultural heritage combining in a holistic way leisure and entertainment experiences [52]. In other words, the process of information sharing is reinforced in terms of historical, cultural and artistic reality, because it is understood, lived, evaluated and shared by users in an ongoing experience exchange.

The revolution boosted by digital technologies, starting a process of culture socialization which implies for cultural organizations a paradigm changes in their offering making. The new interactive modes as well as the creative forms of users' participation paved the ground for the contribution that the emergent 
technologies, acting as intermediaries of connection [53], might offer not only in fostering ongoing processes of cultural value creation [20] [54], but also in re-conceptualizing the meaning of the cultural product [55]. In fact, assuming S-D Logic perspective [24], the cultural product is embedded in an interactional logic, according to which the active users' involvement and a process of mutual adjustment lead to co-create value though an ongoing experience-for-experience exchange.

\subsection{E-Cultural Value Co-Creation}

According to SD logic, service is intended as the application of one entity's knowledge and skills (specialized competences or operant resources) to benefit another [18], being the basis of exchange and focusing on a phenomenological or experiential view of value [56]. This shed lights on interactional nature of service, according to which interactions at least two entities lead mutually create service and that its value emerges from ongoing service-for-service exchange, in which are mainly exchanged operant resources provided through users' active participation [57].

Moving back to cultural value, it is intended as rising from service-for-service exchanges or according to our conceptualization experience-for-experience exchanges that lead to approach cultural heritages as less hedonic, elitist and static and rather as dynamically related to the context in which new and open interactions among and between several different actors [11] nourish processes of value creation. In this vein, the intriguing meaning attached to cultural product mainly roots on the swinging from its intrinsic value towards value in use. In such, value is co-produced and transformed by users, being the result of actors' active transformation and consumption of value offerings [17] [18]. However, value-in-use, individually created and determined, is strictly context dependent, being a unique and unpredictable phenomenon shaped by a peculiar context. More in details, value-in-use does not rise in a vacuum, but it is embedded in a social context and influenced by market practices. In this direction, Vargo et al. [24] maintained that the concept of value in use does not completely grasp the phenomenological nature of value, consequently they further discuss the concept of value-in-context to better define the influence that the context itself plays on the creation and the assessment of value. More in details, the authors contended that the co-creation of value is influenced not only by the implemented and exchanged resources, but also by contextual factors, e.g. culture, knowledge, relationships networks [19] as well as by social structures [58]. Therefore, value-in-context arise from the interactions occurring among a number of actors in a specific place and at a given period of time, being also phenomenologically determined by the extant resource and by the accessibility of other integrating resource, which depends on actors' disposition. For example, a customer's experience at a famous museum depends not only on the notoriety of the exhibited artefacts (e.g. intrinsic value) provided in a specific museum's gallery (service 
encounter), but also on service provider capability in shaping the context in which the customer might realize an immersive service experience. To do this, the active involvement of customer is fundamental to enhance his/her consumption experience through resource integration. Accordingly, what is needed is a customer emotional engagement and at the same time create a servicescape able to catch customers' experiences and expectations. These latter are influence by past experiences, beliefs, values and social ties, since cultural services are deeply subjective, idiosyncratic, and heterogeneous; thus, the expectations, impressions, experiences, and interpretations about a cultural experience highly change from individual to individual.

An experiential approach to cultural product [59] [60] implies that customer has to be engagement in experience seeking, because he/she plays an active role in the creation of a cultural experience [61] sharing (positive and/or negative) emotions not only related to the cultural artefact itself, but above all in his/her customer's network. More in details, these experiences are influenced not only by customers' subjective sociographic characteristics (e.g. education, culture, sex, age, etc.) and feelings (drama, excitement, joy, etc.), but also by their network, made up of friends, families, colleagues and similar. This is strictly related to the conceptualization of value in terms of experience [56], where experience, as stated before, is open to the contribution and the engagement in value creation process of multiple actors' others from the provider-customer dyad [62]. In this vein, digital platforms represent a real enabler of actors' engagement [56] [63] [64], shaping the specific (real and/or virtual) context in which value can be differently co-created according to their phenomenological intentions, feelings and capabilities (skills and knowledge) [65]. In this sense, digital platforms not only shape the context of interactions, but also make the servicescape an immersive environment, in which virtual learning and/or leisure experiences can be always shared and re-created. Therefore, e-cultural value spreads from the dyadic interactions provider-user in which this latter represent a value creator combining and recombining his/her experiences, while the provider acts as facilitator reinforcing or enabling user's experiences in their actors' network. More in detail, technological tools through real-time interactions nourish an ongoing process of value creations enabling the sharing of virtual experiences within the actors' network. Therefore, cultural value goes beyond the individual experience of cultural heritage as well as the traditional dyad provider-user, paving the way for the multiple and networked interactions at the core of value-in-context. This is mainly due to the fact that value rise from relationships between the cultural organization and the actors differently involved in cultural service provision, such as, for example, other cultural organizations or other local actors that (offline and online) interact with each other. It follows that the concept of value opens its boundaries to include a service network orientation [66] that offers a multi-dimensional and multi-actor perspective of cultural product, able to enhance cultural value in a holistic way. In this sense, value is no more generated 
through a chain of linear actions, but through complex relational constellations-which highlight the shifting from a one-to-one/one-to-many orientation towards a many-to-may orientation made up of different actors, who act within the constellation and co-create value, sharing resources through digital levers [67]. In line with this trend, cultural organizations act as multi value and multi service providers [68], because they perform as value conductors for the involved actors (e.g. project designer, hardware/software consultants, consumers, art critics and experts, users, etc.). In this direction, the process of value co-creation can be nourished and multiplied, because all the involved actors are engaged to mutually share their own resources.

\section{The Proposed Model}

The review of literature suggests interesting insights. First, drawing on the renewed process of culture diffusion and fruition, ICTs boosted the development of virtual communities of actors (or users), which makes them capable at accessing digital content through mediated communication protocols that do not require their physical presence. Second, the communicative logic at the roots of these virtual communities has shifted from a push communication, which channels and the related content were developed by providers to hook users, toward a pull communication. This latter orientation is built upon an interactive logic which looks at users as active contributors to online communication, capable at creating their own contents and, at the same time, at directly communicating with cultural organizations. This led to a shifting from the traditional and constraining logic of mass communication-directed to wide, heterogeneous and anonymous audience towards an open and social communication, which is informal, unplanned and encouraged by free information exchange between multiple actors widely boosted by those ICTs and digital technologies [69] which have paved the way for the socialization of culture.

Cultural organization implementing a proprietary platform can act as a value facilitator. However, the co-creation of cultural value depends on the way the platform is managed. In fact, describing an evolution path, digital platform allows to create value-in-use (see Figure 1), because the organization developed interactive, but still dyadic interactions with a single user (one-to-one) or with multiple users (one-to-many). It worth noting that users are capable at acting as value creators thanks to the potential of digital technologies only when they are

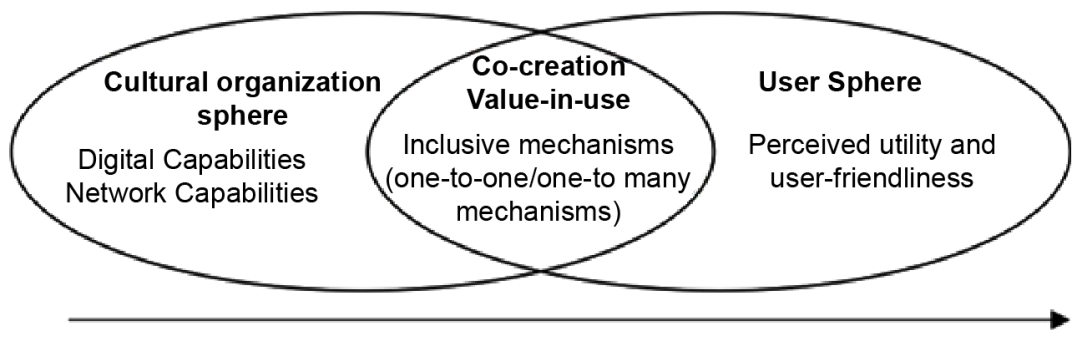

Figure 1. Interactions pointing to value-in-use. 
emotionally engaged in the service interactions mediated by user-friendly digital channel.

In that case, value co-creation assumes a linear orientation, being based on those inclusive practices that the organization develop and promote. Even if these practices are co-created and co-participated, they are still characterized by a Good Dominant (GD) Logic, according to which service is mere component of the cultural product.

In the cultural organization sphere, the co-creation process need for two principal capabilities, the digital ones and the relational ones. The formers are fundamental for the implementation of a platform that effectively catch and store users' information and experiences, while the seconds are fundamental in identifying and involving real and virtual interlocutors. It follows that due to those capabilities the cultural organization enacts proper inclusive mechanisms, pointing to include the user (one) or more than one user (many) in its value propositions (e.g. through the development of an interactive corporate website, virtual tours, online discussion forums, interactive games, etc.).

The digitalization has gradually led to overcome the above-mentioned linear process of value co-creation; thus, the new digital sphere that it contributes to shape boost the emergence of a wider and participative relational network. In particular, this call for embracing the SD Logic in order to enhance the value-in-context in the domain of cultural services. According to this logic, actors (e.g. individuals, other cultural organizations, institutions, etc.) belonging to the same value chain (e.g. museums, art galleries, libraries, etc.) as well as other actors (e.g. travel agencies, restaurants, coffee bars, etc.) interacts-thanks to the digital platform developed by the cultural organization-not only with the organization itself (one-to-one and one-to-many), but also among them (bottom-up many-to-many). These complex and ongoing interactions generate value-in-context [19] which is the value co-created within the relational network thanks to the enabling role of digital technologies, which support the organization in assuming the role of multi-value and multi-service provider [68].

We operationalize what it has been argument before proposing the e-cultural co-creation model (see Figure 2). This model is built upon a focal cultural organization which, through its digital and network capabilities, makes a property platform able to bundle the users' constellation. Thus, users belonging to heterogeneous categories take the platform up in order to integrate online the massive amount of operant resources (e.g. skills, information, knowledge, etc.) that each of them hold. In fact, in the World Wide Web the enhancement of cultural heritage necessarily roots on intangible resources which might continuously add further contents to a specific cultural product. More in depth, in a value co-creation perspective, the above-mentioned resources need to be integrated to generate new and more complying value propositions. The shared information and experiences need to be embedded in a digital platform which structure is intended as service platform that is modular and based on multiple actors' 


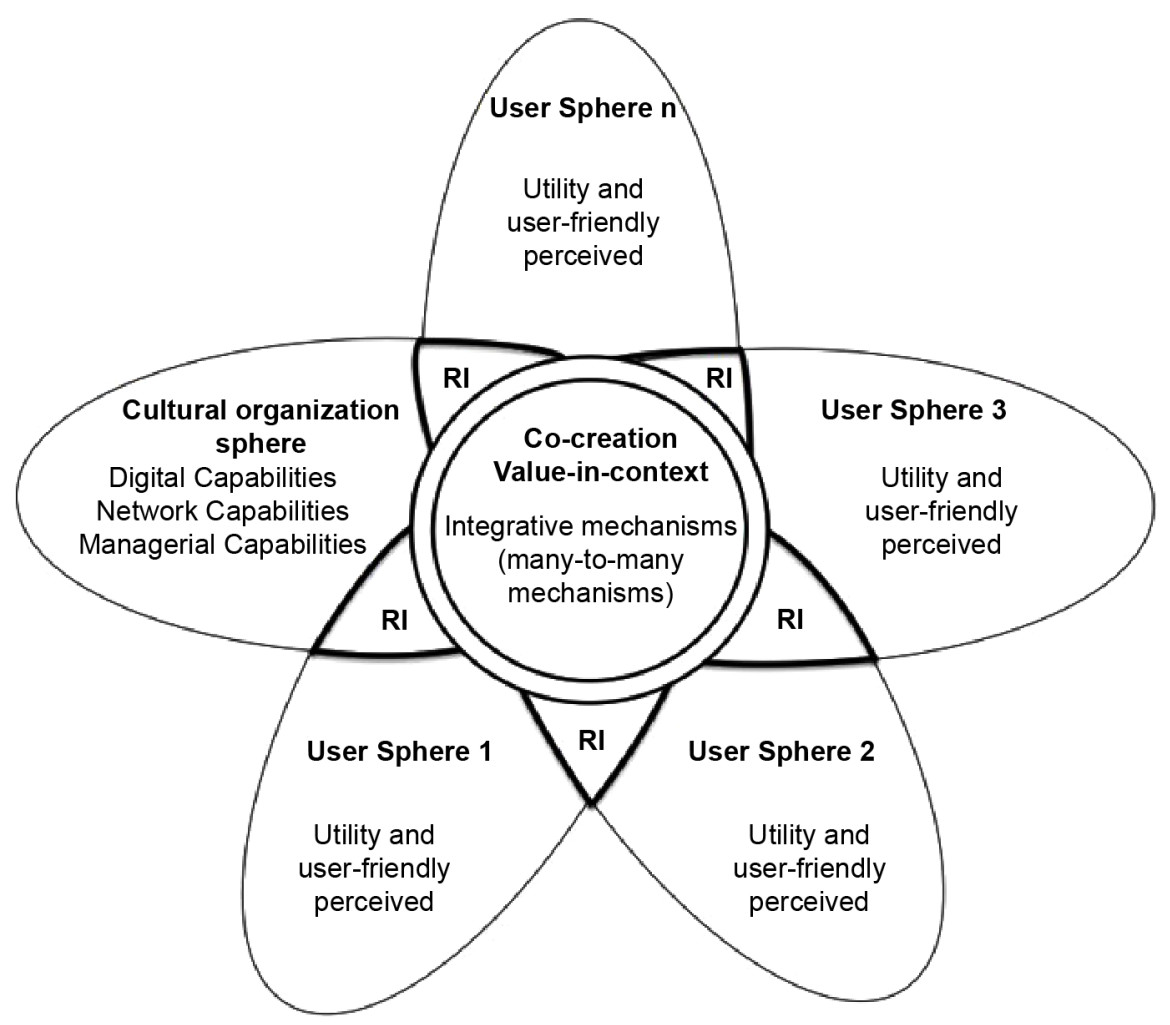

Figure 2. The e-cultural co-creation model.

interactions, intended to share tangible and intangible resources [70]. In this vein, cultural organizations acting as cultural service systems integrate people, technologies, processes and information [71]. More in detail, cultural service systems, being strictly linked to users through the digital lever, nourish ongoing processes of resource integration [72] [73] [74], adapting themselves through interactions and resource integration that are mutually beneficial [24]. In this direction, they actively contribute to the value creation process of other service systems-belonging in our case to the same constellation-enhancing resource density and liquefaction through an ongoing resource re-bundling [72]. The density is the measure of "the best resource combination activated in a specific situation" [75] and in a digital era in which the spatial and temporal dimension fade away and the contents turn into dematerialized, this re-bundling process handles disaggregated and liquefied resources (e.g. the cultural knowledge transmitted though the web, etc.) which can be widely used in the constellation.

The increased possibility in liquefying and sharing information-due to the multimedia, digitalization, informatics and similar-lead not only to the rising of new market offerings, but also to the reconfiguration of service systems on which markets lies upon. This theoretical substrate is explicated in the model proposed in the Figure 2, in which is depicted a cultural organization holding preliminary digital and relational capabilities and which manage the platform.

This organization, being a primary service system, is capable at shape a users' constellation (e.g. other cultural and art organization, virtual visitors, etc.), 
which-interacting through the platform-co-create value integrating online their own information and experiences [73] for the enhancement of the overall heritage culture.

Integrative mechanisms (e.g. comments, feedbacks, blogs, video blogs, etc.) boosted resource integration because they do not merely endorse users in the value proposition (e.g. inclusive mechanisms), but built it together with them. In the model, value is co-created in the intersections between the ellipses through processes of resource integration (RI); thus, this is the loci of the exchange in which the knowledge of one user is applied for the benefit of another. Consequently, the value-in-context is linked to the context and phenomenologically determined. In such, cultural service systems need to manage the digital lever to make knowledge integration able to turn into their concrete application to enrich cultural heritage with further contents and thoughts rather than merely promoting it. Thus, in the proposed model, ICTs are not more or not represent just a tool designed to broadcast aseptic cultural information, but they are exploitation tools designed to share knowledge. In this renewed scenario, the cultural organization need for not only digital and network capabilities, but also service managerial ones, which through the digital platform can enhance an ongoing resource exchange in even more extended actors' constellations to boost value-in-context.

\section{Model Exemplification: The National Museum of Scotland Network}

Drawing on the available digital platforms, which symbolize the new conceptualization of cultural product, one of the most impressive and interesting is the platform implemented at the National Museums of Scotland, which the National Museum of Scotland, the National Museum of Flight, the National Museum of Rural Life and the National War belong. The platform has been designed with accuracy of both layout and contents in order to offer a high rate of user-friendliness and make contents easy to access. It also offers a section dedicated to each of the above-mentioned four museums, which are rich of photos, videos, descriptions and online games. Then, the social users on the most popular social networks (e.g. Facebook, Twitter, Tumblr, Reddit, etc.) can easily share all these contents. One of the most interesting functions that this platform offers let users able to find out the different commercial and catering activities which offer their products and services at special prices for people who bought the thicket for the museum online. Accessing the online platform, users can also organize their own tour thanks to the great amount of information offered through maps, timetables, and transportation information and similar. To easily manage the online functionalities described before, an e-commerce function and a blog has been developed. In particular, the e-commerce function offers to users a wide range of products (e.g. gadgets, accessories, games, household and office articles, etc.) which can be delivered all over the world, while the blog has been 
developed to make art, history or science experts able to post different, but comprehensible contents, which users can access, comment and share.

Drawing on the above-mentioned elements, the case of National Museums of Scotland can be re-conceptualized as a network based on value-in-context creation facilitated by the ICTs. In particular, the Figure 3 depicts the application of the model, discusses in the previous paragraph, to the analyzed case. Resources that each user share in the network are integrated by the online platform which validate, share and make them as coherent as possible. It follows that the platform catalyzes the value co-creation process towards the user, because without this digital channel resources could be shared just in a separate way or if shared together, this process will take a longer time.

\section{Theoretical and Managerial Implications}

The digital lever has contributed to the reshaping of the entire cultural domain, calling for a managerial approach able to run those activities and interactions that generate immersive service experiences or, in other words, co-constructed value-propositions. Thus, the technological advancement and the subsequent introduction of new digital tools have deeply changed the processes of culture diffusion and fruition, which call cultural organizations for acting as service systems, integrating people, technologies, processes and information in order to create mutual benefits [24]. In this vein, the study conceptualized a model which describes the co-creation of e-cultural value. The proposed model opens to interesting implications both theoretical and managerial.

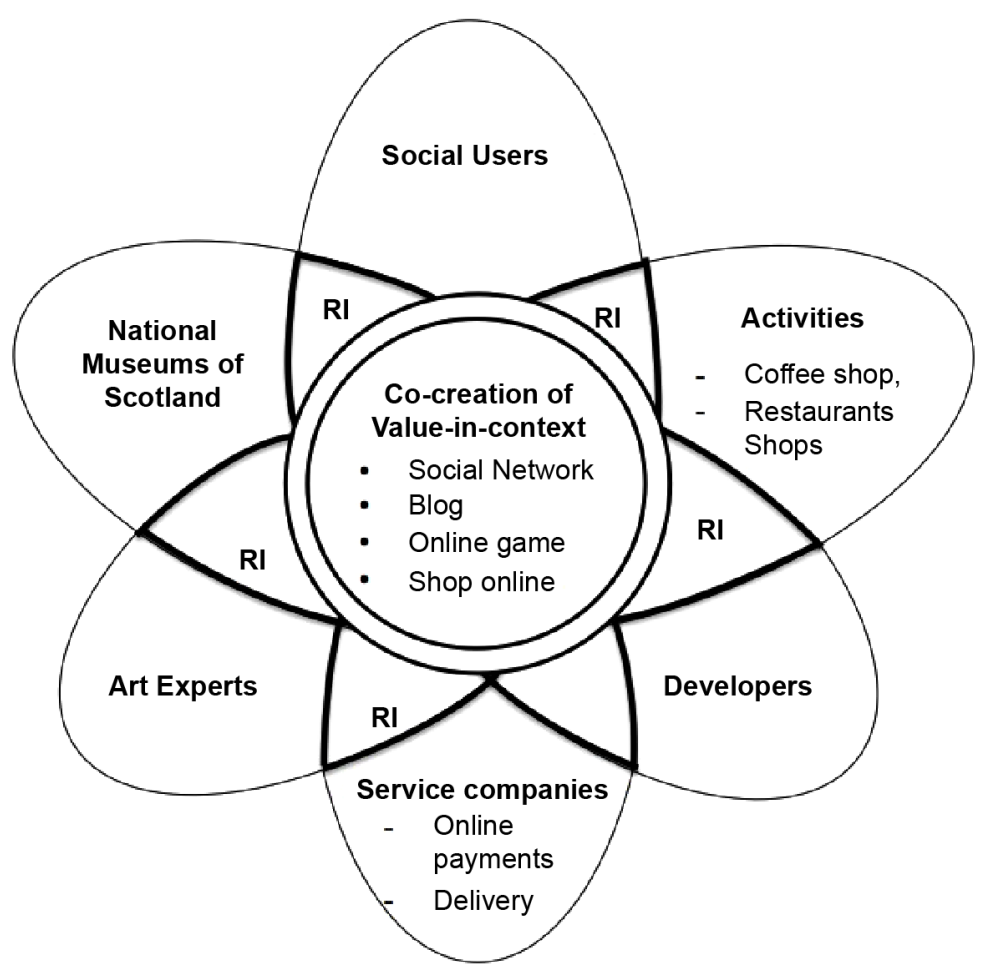

Figure 3. Interactions pointing to co-create e-cultural value. 
In terms of theoretical implications, the study adds to service management literature highlighting how in cultural domain the concept of value-in-context has gone beyond the value-in-use, offering a better conceptualization of resource integration in terms of actors' knowledge sharing. This has led to achieve a wider and superior knowledge that benefit and enhance not only the involved users, but also the whole cultural heritage. In this sense, the cultural organization can be considered a service system integrator, which aim is facilitating the integration of resources-e.g. people, organizations, technologies, shared information and consequently extending the context in which (e) cultural value is created. This is possible only when digital platforms act as operant resources, that is when they engage human actors and digital artefacts in service interactions [64], enhancing actors disposition to jointly share resource integration activities. Drawing on Lusch and Nambisan [70] conceptualization, a digital platform can be intended as both operand resource (e.g. as the enabler of multilevel actors' interactions) and operant resource (e.g. as an actor directly involved in the institutionalization of a social/market change). More in details, assuming the focal actor perspective (e.g. the cultural organization) effective patterns of resource integration-enabled by platforms that foster cognitive, emotional and behavioral engagement-align actors' disposition whiting and across different environments (e.g. digital and physical spaces, processes and activities) to an ongoing service-for-service exchange. In this way, service experience depends on the enduring and dynamic alignment of many actors' connections and disposition. Being a digital platform able to physically and virtually engage actors and their agency to act together (co-create e-value), it can consequently contribute to the institutionalization of norms, rules, habits and new meanings fundamental to shape a cultural service ecosystem. In this sense, in cultural heritage domain, digital platforms can act as an institutional arrangement enabled by cultural organization agency, marking the context in which actors exchange experience-for-experience to co-create e-value, shaping a cultural service ecosystem (see Figure 4).

As the figure shows, a cultural service ecosystem is shaped when different resources of integrating actors are connected by shared institutional arrangements to create mutual value through actors' disposition in sharing service experiences. In terms of managerial implications, the proposed model is aimed at boosting the management of cultural organizations in defining together with users smarter offering, which smartness is due to the use of digital platforms intended not only as communication tools as usually happens in the most of cultural organizations-but as an interactive platforms pointing to enhance cultural heritage. This enhancement is mediated by contents enrichment due to synergistic processes of resource integration. In this direction, managers need to create a service infrastructure that develops specific and recurrent touch points for co-creation that enable users not only to participate, but also to become active co-creators of their own experience. 


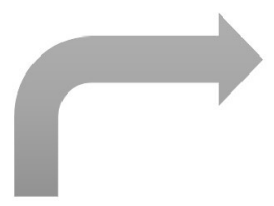

Service Ecosystem

Nested and overlapping

(micro, meso, macro)

Institutions and

Institutional arrangements

Endogenously generate

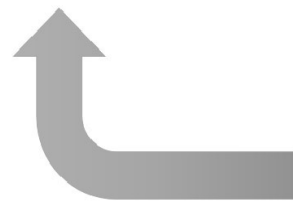

Co-creation

of

value-in-context

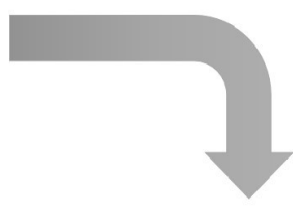

Actors

Users

Cutural organization

Other service organizations

Public Institutions

\section{Experience-for- experience exchange \\ Enabled and constrained by the digital platform}

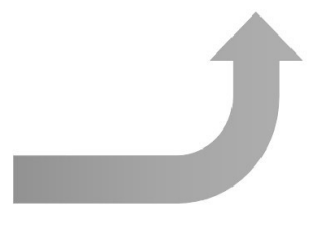

Figure 4. The co-creation of value-in-context to shape a cultural service ecosystem.

Last but not least, the proposed model should support the heritage management in boosting the attractiveness of the total territorial areas and, if implemented according to the logic previously described, it can foster the shaping of a cultural service ecosystem.

\section{Conclusions and Further Remarks}

This study has briefly reviewed the main contribution on cultural heritage enhancement and on the co-creation process of value in cultural domain, focusing on the importance of users as well as different actors' networks, based on dense virtual relationships, in value co-creation [76]. In particular, the analysis has been intended at responding at the two research questions which inspired the paper and which draw upon the relationship existing between e-culture and value-co-creation. In so doing, the proposed theoretical model depicts how users and cultural organizations interact according to a value-in-context perspective. The above-mentioned perspective has been embraced because being different from the simple value-in-use perspective, it boost the comprehension of the non-linear process that cultural organizations enact to co-create meaningful service experiences. These organizations are embedded in close network of relationships in which user or actor belonging to the same service context (e.g. other cultural organizations), or to other service domains (e.g. tourism, hospitality, transportation, etc.) integrate their own resources in order to co-create value according to a bottom-up many-to-many logic supported by specific digital platforms. In this vein, SD Logic represents a valuable theoretical framework according to which it is possible to achieve a deeper comprehension of those mutual and dynamic actors' interactions at the core of cultural value. At the same time, the proposed model also calls for a better understanding of resource integration in co-creation of value [77]. 
Finally, this study paves the way for future research pointing to define and depict a context of experience shaped by the interactions of multiple actors boosted by digital platforms and aimed at co-create (e) cultural value according to an institutional logic. In sum, the results achieved through this study represent a starting point for further development, pointing to test the proposed model through an empirical implementation in specific cultural service ecosystem.

\section{Author Contributions}

The work is the result of all the authors' synergistic contribution. However, each author has dealt with some paragraphs more than others. More in detail: Maria Vincenza Ciasullo has written Sections 3.3, 4, and 6; Orlando Troisi has written Sections 2, 3.2, 5, and 7; Silvia Cosimato has elaborated Sections 1, and 3.1.

\section{Conflicts of Interest}

The authors declare no conflict of interest.

\section{References}

[1] Golinelli, G.M. (2015) Cultural Heritage and Value Creation. Towards New Pathways. Switzerland, Springer.

[2] Alivizatou, M. (2016) Intangible Heritage and the Museum: New Perspectives on Cultural Preservation. Routledge, New York.

[3] Timothy, D.J. (2017) Managing Heritage and Cultural Tourism Resources: Critical Essays. Vol. 1. Routledge, London.

[4] Mcdonald, S. (1998) The Politics of Display: Museums, Science, Culture. Psychology Press, New York.

[5] Goulding, C. (2000) The Museum Environment and the Visitor Experience. European Journal of Marketing, 34, 261-278. https://doi.org/10.1108/03090560010311849

[6] Tallon, L. and Walker, K. (2008) Digital Technologies and the Museum Experience. Altamira Press, New York.

[7] Falk, J.H. and Dierking, L.D. (2016) The Museum Experience Revisited. Routledge, London.

[8] Kasemsap, K. (2013) Unifying a Framework of Organizational Culture, Organizational Climate, Knowledge Management, and Job Performance. In: Perez-Castillo, R. and Piattini, M.G., Eds., Uncovering Essential Software Artifacts through Business Process Archeology, ABISA Book Series, New York, 336-362.

[9] Gilmore, A. and Rentschler, R. (2002) Changes in Museum Management: A Custodial or Marketing Emphasis? Journal of Management Development, 21, 745-760. https://doi.org/10.1108/02621710210448020

[10] Sandell, R. and Janes, R.R. (2007) Museum Management and Marketing. Routledge, London.

[11] Barile, S. and Saviano, M. (2015) From the Management of Cultural Heritage to the Governance of the Cultural Heritage System. In: Golinelli, G., Ed., Cultural Heritage and Value Creation, Springer International Publishing, Cham, 71-103. https://doi.org/10.1007/978-3-319-08527-2_3 
[12] Cohen, S.A., Prayag, G. and Moital, M. (2014) Consumer Behavior in Tourism: Concepts, Influences and Opportunities. Current Issues in Tourism, 17, 872-909. https://doi.org/10.1080/13683500.2013.850064

[13] Montella, M. (2015) Cultural Value. In: Golinelli, G., Ed., Cultural Heritage and Value Creation, Springer, Cham, 1-51. https://doi.org/10.1007/978-3-319-08527-2_1

[14] Chen, C.F. and Chen, F.S. (2010) Experience Quality, Perceived Value, Satisfaction and Behavioral Intentions for Heritage Tourists. Tourism Management, 31, 29-35. https://doi.org/10.1016/j.tourman.2009.02.008

[15] Barile, S., Montella, M. and Saviano, M. (2012) A Service Based Systems View of Cultural Heritage. Journal of Business Market Management, 5, 106-136.

[16] Ciasullo, M.V., Gaeta, A., Gaeta, M. and Monetta, G. (2016) New Modalities for Enhancing Cultural Heritage Experience. The Enabling Role of Digital Technologies. Sinergie Italian Journal of Management, 34, 119-139.

[17] Vargo, S. and Lusch, R. (2006) The Service-Dominant Logic of Marketing: Dialog, Debate, and Directions. ME Sharpe, Armonk, NY.

[18] Vargo, S. and Lusch, R. (2008) Service-Dominant Logic: Continuing the Evolution. Journal of the Academy of Marketing Science, 36, 1-10. https://doi.org/10.1007/s11747-007-0069-6

[19] Chandler, J.D. and Vargo, S.L. (2011) Contextualization and Value-In-Context: How Context Frames Exchange. Marketing Theory, 11, 35-49. https://doi.org/10.1177/1470593110393713

[20] Bakhshi, H. and Throsby, D. (2012) New Technologies in Cultural Institutions: Theory, Evidence and Policy Implications. International Journal of Cultural Policy, 18, 205-222. https://doi.org/10.1080/10286632.2011.587878

[21] Lenka, S., Parida, V., Sjödin, D.R. and Wincent, J. (2016) Digitalization and Advanced Service Innovation: How Digitalization Capabilities Enable Companies to Co-Create Value with Customers. Management of Innovation and Technology, 3, $2-5$.

[22] Lenka, S., Parida, V. and Wincent, J. (2017) Digitalization Capabilities as Enablers of Value Co-Creation in Servitizing Firms. Psychology \& Marketing, 34, 92-100. https://doi.org/10.1002/mar.20975

[23] Holmlund, M., Strandvik, T. and Lähteenmäki, I. (2017) Digitalization Challenging Institutional Logics: Top Executive Sensemaking of Service Business Change. Journal of Service Theory and Practice, 27, 213-230. https://doi.org/10.1108/JSTP-12-2015-0256

[24] Vargo, S., Maglio, P. and Akaka, M.A. (2008) On Value and Value Co-Creation: A Service Systems and Service Logic Perspective. European Management Journal, 26, 145-152. https://doi.org/10.1016/j.emj.2008.04.003

[25] Vargo, S. and Lusch, R. (2012) The Nature and Understanding of Value: A Service-Dominant Logic Perspective. Review of Marketing Research, 9, 1-12. https://doi.org/10.1108/S1548-6435(2012)0000009005

[26] Vargo, S. and Lusch, R. (2017) Service-Dominant Logic 2025. International Journal of Research in Marketing, 34, 46-67. https://doi.org/10.1016/j.ijresmar.2016.11.001

[27] Hart-Davidson, W. and Grabill, J. (2012) The Value of Computing, Ambient Data, Ubiquitous Connectivity for Changing the Work of Communication Designers. Communication Design Quarterly, 1, 16-22. https://doi.org/10.1145/2448917.2448921 
[28] Tilson, D., Lyytinen, K. and Sørensen, C. (2010) Research Commentary-Digital Infrastructures: The Missing Is Research Agenda. Information Systems Research, 21, 748-759. https://doi.org/10.1287/isre.1100.0318

[29] Lemley, T. and Burnham, J.F. (2009) Web 2.0 Tools in Medical and Nursing School Curricula. Journal of the Medical Library Association, 97, 50-52. https://doi.org/10.3163/1536-5050.97.1.010

[30] Kozinets, R.V. (2010) Netnography: Doing Ethnographic Research Online. Sage Publications, London.

[31] Aghaei, S., Nematbakhsh, M.A. and Farsani, H.K. (2012) Evolution of the World Wide Web: From WEB 1.0 to WEB 4.0. International Journal of Web \& Semantic Technology, 3, 1-10. https://doi.org/10.5121/ijwest.2012.3101

[32] Murugesan, S. (2007) Understanding Web 2.0. IT professional, 9, 34-41. https://doi.org/10.1109/MITP.2007.78

[33] Jensen, K.B. and Helles, R. (2017) Speaking into the System: Social Media and Many-To-One Communication. European Journal of Communication, 32, 16-25. https://doi.org/10.1177/0267323116682805

[34] Garrigos-Simon, F.J., Lapiedra Alcami, R. and Barbera Ribera, T. (2012) Social Networks and Web 3.0: Their Impact on the Management and Marketing of Organizations. Management Decision, 50, 1880-1890. https://doi.org/10.1108/00251741211279657

[35] Rahaman, H. and Tan, K.B. (2011) Interpreting Digital Heritage: A Conceptual Model with End-User's Perspective. International Journal of Architectural Computing, 9, 99-112. https://doi.org/10.1260/1478-0771.9.1.99

[36] Kollmann, T., Lomberg, C. and Peschl, A. (2016) Web 1.0, Web 2.0, and Web 3.0: The Development of E-Business. In: Lee, I., Ed., Encyclopedia of E-Commerce Development, Implementation, and Management, IGI Global, Hershey, 1139-1148. https://doi.org/10.4018/978-1-4666-9787-4.ch081

[37] Choudhury, N. (2014) World Wide Web and Its Journey from Web 1.0 to Web 4.0. International Journal of Computer Science and Information Technologies, 5, 8096-8100.

[38] Patel, K. (2013) Incremental Journey for World Wide Web: Introduced with Web 1.0 to Recent Web 5.0-A Survey Paper. International Journal of Advanced Research in Computer Science and Software Engineering, 3, 112-125.

[39] Martínez-López, F.J., Anaya-Sánchez, R., Aguilar-Illescas, R. and Molinillo, S. (2016) Evolution of the Web. In: Online Brand Communities, Progress in IS, Springer International Publishing, London, 5-15. https://doi.org/10.1007/978-3-319-24826-4_2

[40] Gray, J. and Rumpe, B. (2015) Models for Digitalization. Software \& Systems Modeling, 4, 1319-1320. https://doi.org/10.1007/s10270-015-0494-9

[41] Abras, C., Maloney-Krichmar, D. and Preece, J. (2004) User-Centered Design. In: Bainbridge, W., Ed., Encyclopedia of Human-Computer Interaction, Sage Publications, Thousand Oaks, CA, 445-456.

[42] Belk, R. (2014) You Are What You Can Access: Sharing and Collaborative Consumption Online. Journal of Business Research, 67, 1595-1600. https://doi.org/10.1016/j.jbusres.2013.10.001

[43] Bertacchini, E. and Morando, F. (2013) The Future of Museums in the Digital Age: New Models for Access to and Use of Digital Collections. International Journal of Arts Management, 15, 60-72. 
[44] Terranova, T. (2000) Free Labor: Producing Culture for the Digital Economy. Social text, 18, 33-58. https://doi.org/10.1215/01642472-18-2_63-33

[45] Finnis, J. (2008) Turning Cultural Websites Inside Out: Changes in Online User Behaviour, Web 2.0 and the Issues for the Culture Sector. In: Uzelac, A. and Cvjeticanin, B., Eds., Digital Culture: The Changing Dynamics, Culturelink Joint Publications, Zagreb, 151-165.

[46] Lehdonvirta, V. (2012) A History of the Digitalization of Consumer Culture: From Amazon through Pirate Bay to FarmVille. In: Molesworth, M. and Knott, J.D., Eds., Digital Virtual Consumption, Routledge, London, 2-30.

[47] Ray, S. (2014) Colonial Frames, "Native" Claims: The Jaipur Economic and Industrial Museum. The Art Bulletin, 96, 196-212. https://doi.org/10.1080/00043079.2014.899180

[48] Economou, M. (2016) Heritage in the Digital Age. In: Logan, W., Craith, M.N. and Kockel, U., Eds., A Companion to Heritage Studies, Wiley, Chichester, 215-228.

[49] Mechant, P. (2007) Culture 2.0: Social and Cultural Exploration through the Use of Folksonomies and Weak Cooperation. Cultuur 2.0 Virtueel Platform, 9, 21-26.

[50] Thomas, S. (2015) Digital Media in Museums: A Personal History. In: Din, H. and Wu, S., Eds., Digital Heritage and Culture: Strategy and Implementation, World Scientific, Hackensack, NJ, 119-130.

[51] Simon, N. (2010) The Partecipatory Museum. Museum 2.0, Santa Cruz, CA.

[52] Reunanen, M., Díaz, L. and Horttana, T. (2015) A Holistic User-Centered Approach to Immersive Digital Cultural Heritage Installations: Case Vrouw Maria. Journal on Computing and Cultural Heritage (JOCCH), 7, 1-16. https://doi.org/10.1145/2637485

[53] Lusch, R.F., Vargo, S.L. and Gustafsson, A. (2016) Fostering a Trans-Disciplinary Perspectives of Service Ecosystems. Journal of Business Research, 69, 2957-2963. https://doi.org/10.1016/j.jbusres.2016.02.028

[54] Chiabai, A., Paskaleva, K. and Lombardi, P. (2013) e-Participation Model for Sustainable Cultural Tourism Management: A Bottom-Up Approach. International Journal of Tourism Research, 15, 35-51. https://doi.org/10.1002/jtr.871

[55] Barrett, M., Davidson, E., Prabhu, J. and Vargo, S.L. (2015) Service Innovation in the Digital Age: Key Contributions and Future Directions. MIS Quarterly, 39, 135-154. https://doi.org/10.25300/MISQ/2015/39:1.03

[56] Prahalad, C.K. and Ramaswamy, V. (2004) Co-Creation Experiences: The Next Practice in Value Creation. Journal of Interactive Marketing, 18, 5-14. https://doi.org/10.1002/dir.20015

[57] Polese, F., Pels, J., Tronvoll, B., Bruni, R. and Carrubbo, L. (2017). A4A Relationships. Journal of Service Theory and Practice, 27, 1040-1056. https://doi.org/10.1108/JSTP-05-2017-0085

[58] Edvardsson, B., Tronvoll, B. and Gruber, T. (2011) Expanding Understanding of Service Exchange and Value Co-Creation: A Social Construction Approach. Journal of the Academy of Marketing Science, 39, 327-339. https://doi.org/10.1007/s11747-010-0200-y

[59] Holbrook, M.B. and Hirschman, E.C. (1982) The Experiential Aspects of Consumption: Consumer Fantasies, Feelings, and Fun. Journal of Consumer Research, 9, 132-140. https://doi.org/10.1086/208906

[60] Brakus, J.J., Schmitt, B.H. and Zhang, S. (2014) Experiential Product Attributes and Preferences for New Products: The Role of Processing Fluency. Journal of Business 
Research, 67, 2291-2298. https://doi.org/10.1016/j.jbusres.2014.06.017

[61] Yu Park, H. (2010) Heritage Tourism: Emotional Journeys into Nationhood. Annals of Tourism Research, 37, 116-135. https://doi.org/10.1016/j.annals.2009.08.001

[62] Akaka, M.A., Vargo, S.L. and Schau, H.J. (2015) The Context of Experience. Journal of Service Management, 26, 206-223. https://doi.org/10.1108/JOSM-10-2014-0270

[63] Breidbach, F., Brodie, R. and Hollebeek, L. (2014) Beyond Virtuality: From Engagement Platforms to Engagement Ecosystems. Managing Service Quality, 24, 592-611. https://doi.org/10.1108/MSQ-08-2013-0158

[64] Storbacka, K., Brodie, R.J., Böhmann, T., Maglio, P.P. and Nenonen, S. (2016) Actor Engagement as a Microfoundation for Value Co-Creation. Journal of Business Research, 69, 3008-3017. https://doi.org/10.1016/j.jbusres.2016.02.034

[65] Edvardsson, B., Kristensson, P., Magnusson, P. and Sundström, E. (2012) Customer Integration within Service Development-A Review of Methods and an Analysis of In Situ and Ex Situ Contributions. Technovation, 32, 419-429. https://doi.org/10.1016/j.technovation.2011.04.006

[66] Barile, S. and Polese, F. (2010) Linking the Viable System and Many-to-Many Network Approaches to Service-Dominant Logic and Service Science. International Journal of Quality and Service Sciences, 2, 23-42. https://doi.org/10.1108/17566691011026586

[67] Barile, S., Ciasullo, M.V., Troisi, O. and Sarno, D. (2017) The Role of Technology and Institutions in Tourism Service Ecosystems: Findings from a Case Study. The TQM Journal, 29, 811-833. https://doi.org/10.1108/TQM-06-2017-0068

[68] Scott, S. (2009) Repackaging Fan Culture: The Regifting Economy of Ancillary Content Models. Transformative Works and Cultures, 3, 111-130. https://doi.org/10.3983/twc.2009.0150

[69] Murthy, D. (2013) Twitter: Social Communication in the Twitter Age. John Wiley \& Sons, London.

[70] Lusch, R.F. and Nambisan, S. (2015) Service Innovation: A Service-Dominant Logic Perspective. MIS Quarterly, 39, 155-177. https://doi.org/10.25300/MISQ/2015/39.1.07

[71] Maglio, P.P., Vargo, S.L., Caswell, N. and Spohrer, J. (2009) The Service System Is the Basic Abstraction of Service Science. Information Systems and e-Business Management, 7, 395-406. https://doi.org/10.1007/s10257-008-0105-1

[72] Vargo, S. and Akaka, M.A. (2009), Service-Dominant Logic as a Foundation for Service Science: Clarifications. Service Science, 1, 32-41.

https://doi.org/10.1287/serv.1.1.32

[73] Vargo, S., Lusch, R. and Akaka, M.A. (2010) Advancing Service Science with Service-Dominant Logics. In: Maglio, P., Kieliszewski, C. and Spohrer, J., Eds., Handbook of Service Science. Service Science: Research and Innovations in the Service Economy, Springer, Boston, MA, 133-156. https://doi.org/10.1007/978-1-4419-1628-0_8

[74] Kleinaltenkamp, M., Brodie, R.J., Frow, P., Hughes, T., Peters, L.D. and Woratschek, H. (2012) Resource Integration. Marketing Theory, 12, 201-205. https://doi.org/10.1177/1470593111429512

[75] Normann, R. (2001). Reframing Business: When the Map Changes the Landscape. John Wiley \& Sons, New York.

[76] Jaakkola, E. and Hakanen, T. (2013) Value Co-Creation in Solution Networks. Industrial Marketing Management, 42, 47-58. 
https://doi.org/10.1016/j.indmarman.2012.11.005

[77] Vargo, S. and Lusch, R. (2016) Institutions and Axioms: An Extension and Update of Service-Dominant Logic. Journal of the Academy of Marketing Science, 44, 5-23. https://doi.org/10.1007/s11747-015-0456-3 